\title{
End of Life and Women Aging with a Disability
}

\author{
Deborah L. Volker, Ph.D., R.N., AOCN, FAAN, Cynthia Zolnierek, M.S.N., R.N., \\ Tracie Harrison, Ph.D., R.N., and Janiece Walker, M.S.N., R.N.
}

\begin{abstract}
Approximately 21 million noninstitutionalized Americans with physical disabilities will ultimately face end-oflife [EOL] issues. Studies have documented disparate care and poorer outcomes for persons with preexisting disabilities who have life-limiting illnesses, which raises the question of how EOL experiences may differ for these individuals. The aim of this qualitative, descriptive study was to explore how EOL issues might emerge within the life stories of women aging with functional disabilities. Interview data were obtained from a larger, ongoing ethnographic study focused on the creation of an explanatory model of health disparities of disablement in women with mobility impairment. Each participant was interviewed three to four times using a life-course perspective that captures life trajectories and transitions experienced over time. For this analysis, 41 interviews were selected from 20 participants who discussed issues related to death and dying. Content analysis of the data revealed five analytic categories: death as a signpost, impact of others' deaths, deaths that affected personal insights and choice, EOL possibilities, and a personal brush with death. EOL issues were manifested in a variety of ways that revealed both determination to remain as independent as possible within the context of declining functional ability and uncertainty regarding the future.
\end{abstract}

\section{Introduction}

D ESPITE RECENT IMPROVEMENTS in end-of-life (EOL) care, disparate patient outcomes within the context of lifelimiting illness exist. In particular, people who have been historically underserved and marginalized by the health care system receive EOL care that is inconsistent with best practices. ${ }^{1-3}$ However, much of the research to date has focused on ethnicity-based differences in care preferences and outcomes. ${ }^{4-7}$ Few studies have focused on the needs of people who have acquired an early onset disability before needing EOL care services. ${ }^{8}$ Yet, approximately 21 million Americans with physical disabilities ${ }^{9}$ will ultimately face EOL issues.

Although most people experience a functional decline at the EOL and become increasingly disabled as death approaches, ${ }^{10}$ the EOL experience may be different for those with a long-term functional limitation prior to needing EOL care. Studies have documented disparate health care and outcomes for persons with disabilities (PWDs). For example, PWDs are less likely to undergo screening exams for cancer and more likely to have poor health conditions or practices (obesity, hypertension, tobacco use) that put them at risk for life-threatening diseases. ${ }^{11}$ Further, disabled Medicare beneficiaries have higher rates of cancer-related mortality for breast and colorectal cancers ${ }^{12}$ and are less likely to receive surgery for certain lung cancers. ${ }^{13}$ These findings raise the question of how EOL care practices might differ for PWDs.

Several models of EOL care delivery have been tested in various settings. ${ }^{14}$ Yet many of these studies focus on targeted groups (e.g., African American, rural, pediatric), do not report whether participants had preexisting functional disabilities prior to entering the studies, and do not indicate whether the intervention was informed by potentially unique needs of PWDs. Thus, the purpose of this study was to explore EOL issues and concerns within the life stories of women aging with mobility limitations. Because America's aging population is predominantly female, ${ }^{9}$ the study of aging women with disabilities represents a unique opportunity to understand EOL issues for a growing population.

\section{Methods}

The study design entailed a qualitative descriptive approach $^{15}$ using interview data from an ongoing ethnographic study focused on creation of an explanatory model of health disablement between groups of women. An institutional review board (IRB) approved the study prior to implementation; all participants gave written informed consent. In the parent study, Mexican American and non-Hispanic white women 55 to 75 years old were recruited throughout Texas, where about 
3 million PWDs live. ${ }^{9}$ Recruitment strategies included use of informal community liaisons, attendance at support groups for PWDs, and distribution of study flyers at health care and social services agencies. We limited the current study to nonHispanic white women because cultural factors in the experience of disablement could yield different issues between the two groups. ${ }^{16}$ An analysis of the Mexican American women's experiences will be conducted and reported separately.

Each participant was interviewed three to four times using a life-course perspective that captures life trajectories and transitions experienced over time. ${ }^{17}$ Interview questions focused on the experience of disablement; examples included queries on how differences in the participant's body affected work and family roles, and times in life that were especially difficult or easy. The sample included all participants enrolled in the parent study at the time of the current study; all interview transcripts (90 from 28 participants) were screened for relevance to our study's aim. If a participant discussed issues regarding her own mortality, the death of family members or friends, advance directives, or beliefs about the EOL, the interview was included for analysis.

Interviews were analyzed using Patton's process for qualitative analysis. ${ }^{18}$ Each interview was reviewed line by line to identify significant statements, ideas, and stories germane to the study. For coding, the data were compared both within and across interviews to identify like groupings of information. Similar groupings of codes were then combined into larger categories to form a more comprehensive understanding of the participants' thoughts. To promote trustworthiness of study findings, the first two study authors analyzed the interview transcripts independently and met periodically to compare findings and resolve discrepancies.

\section{Results}

Forty-one interviews from 20 non-Hispanic white women constituted the final sample (Table 1). Functional disabilities

Table 1. Participant Characteristics $(N=20)$

\begin{tabular}{ll}
\hline Mean age & $62(\mathrm{SD}=5.53)$ \\
Mean years of education & $15(\mathrm{SD}=3.03)$ \\
Marital status & 7 \\
$\quad$ Married & 6 \\
$\quad$ Divorced & 5 \\
Widowed & 1 \\
Living with significant other & 1 \\
Never married & \\
Annual income & 4 \\
Less than $\$ 10,000$ & 3 \\
$\$ 10,000-\$ 15,000$ & 1 \\
$\$ 15,000-\$ 20,000$ & 1 \\
$\$ 20,000-\$ 25,000$ & 1 \\
$\$ 25,000-\$ 35,000$ & 1 \\
\$35,000-\$50,000 & 7 \\
$\$ 50,000-\$ 75,000$ & 2 \\
More than $\$ 75,000$ & $46(\mathrm{SD}=12.64)$ \\
Mean age when lost ability to do & \\
many things they wanted to do & $43(\mathrm{SD}=16.07)$ \\
Mean age when physician told them & \\
they had an illness that would & \\
not go away &
\end{tabular}

included rheumatoid arthritis, myasthenia gravis, back injuries, Charcot-Marie-Tooth syndrome, post-polio syndrome, and others. Five analytic categories were constructed from the interview data:

\section{Death as a signpost}

This category refers to use of another's death as a reference point for remembering the chronology of one's own life story. As participants reflected on key events within their life histories, they often referred to the deaths of family members or friends to recall specifics. One woman described that the death occurred within the context of juggling family responsibilities while seeking medical care for her own health.

\begin{abstract}
"When did I quit [working]? After I went to the doctor after school was out and mother died April 1st and I was going home every weekend during that time because I was making sure that my daddy didn't die. I went to a different neurosurgeon and he said, 'I can't do surgery on you and help you. So you are disabled; you will never step foot in another classroom.'"
\end{abstract}

Other individuals mentioned death almost as an aside within their life stories. For example, one woman recalled the year of her husband's death as a mechanism to remember when she underwent surgical procedures. Another used her father's death for remembering when she broke her neck in an automobile accident and began to focus her energy on providing better care for her family.

\section{Impact of others' deaths}

This category refers to a sense that another's death triggered a decline in the participant's health. One woman recounted a story of her husband's death in a roofing accident:

\begin{abstract}
"My husband had an accident and died, so then I started to have headaches and things, so I had to go to the doctor, and he found out that I had this disease, crippling disease. He said it [usually] won't come on until you're 60 or 70 , but it came on earlier, about in my 50s. He said that probably the reason it came on is because of losing my husband, the trauma of it."
\end{abstract}

She agreed with his assessment and explained, "Yeah, I did start to stumble out there, after he passed away."

Many participants speculated that the stress of experiencing a loved one's death had a direct, negative impact on their health. For example, as one woman recounted giving birth to a stillborn infant decades ago, she shared that "it's getting close to the time my baby died. This is the worst time of the year for me." She then described stomach pains: "It hurts so bad like labor pain. [But] it's all up here [points to head]."

Other participants described experiences with deaths that they believed triggered an increase in their level of disability. One woman with a degenerative bone disease attributed her decline in health to her husband's death:

"Everything happened to me in quick succession when he passed away. I had cancer and I started falling a lot more and bones started breaking that didn't break before. And I fell on my elbow and it was a long time before I could get back to moving it."

\section{Deaths that affected personal insights and choice}

The actual or potential EOL experience of a loved one served as a lens for understanding their personal life and death experience. Overall, the experience of another's illness 
and subsequent death shaped views on life, disability, and subsequent choices. For some, the nature of their loved one's death had an impact on how they viewed their own ability to overcome difficulties. For instance, one participant observed:

"I had the advantage that my mother had it [a disabling neurological disease] before me and everybody knows what to expect, and they expect me to do less than what I do and I'm going to do what I can do as long as I can do it."

As she described her mother's death, she shared that:

"She didn't wanna go to the hospital at all, she would fight it, right up to the day she died, she fought it. She just gradually got to where she couldn't do as much, and by the time that she died, she couldn't hold her neck up. But I thought she was very brave and did a really good job of trying to stay around more for us than for herself."

Although this participant admitted to having panic attacks as her own disease progressed, she also believed that witnessing her mother's experience gave her an advantage for managing her own health.

Other participants found the death of another person in their lives as disturbing when interpreting their own experience. For instance, a woman with a disabling autoimmune disorder described her father's sudden death due to pancreatic cancer. Although she reflected that the quick nature of his death had "some good aspects to it" she also indicated that the experience influenced her worries about her own health and how she interpreted her symptoms. As she described her struggles with severe back pain, she observed that:

"I've been more depressed about health issues than I have in the past. I just keep thinking that it's really not the herniated disk. I probably have pancreatic cancer. I mean, I just keep dwelling on the worst possible scenario."

The nature of a loved one's death was also viewed as having a real or potential direct impact on their personal survival. For instance, participants expressed concern about the impact of a spouse's death on their ability to live independently. A woman described her financial troubles after her husband died and her difficulty managing basic care expenses. Another woman commented on her future relative to her spouse's survival. She described her relationship with her husband as abusive; she stated that he called her a "cripple" and had said, "I'd just get rid of myself if I was in that shape." Yet she also worried that if he left her or died, she would have no help at all.

\section{End-of-life possibilities}

This category refers to discussion about values, choices, and concerns about how the EOL may unfold. For example, participants discussed the impact of their death on others' lives, plans for their care before and after death, and opinions about the use of technology as health declined. This indicated that the women viewed death as a culminating event with societal meaning in terms of financial costs and personal value, which meant it needed thoughtful preparation and resources. The high significance placed on death is demonstrated in one participant's plans to donate her body to a medical center after her death. She was donating her body to pay the facility back for providing care. She explained:

"I didn't have no insurance or nothin' so I donated my body to 'em [a medical center]. It's the least I can do. They kept me alive [when] they told me in 1988 [I had] maybe 2 years. My nephew promised me he would transport my body back [to the medical center], but I had to write a letter, because he's scared my sons are going to object. I don't want a funeral. I don't want a ceremony."

The meaning of life also affected the women's views of technology. Where the use of technology could amplify their deficits when viewed by those without disabilities, these women spoke of life-sustaining technology and assistive devices as vital components of everyday living. This is in contrast to others' opinions who have viewed such technology as too burdensome for use. This is evident in a participant's story about her dependence on renal dialysis. She described her interaction with a friend with poorly controlled diabetes. "I just kept telling her, 'You can lose your sight, limbs, end up on dialysis like me,' and she said, 'Oh, I'll just go ahead and die if I had to go on dialysis.'" The participant said she felt terrible that her friend would feel that way: "It's a life-saving thing!"

The women's value of life was evident in their discussions about death. Participants discussed dying as a poor alternative to the unexpected bodily changes that accompany many disabling conditions. A participant with severe movement limitations due to scleroderma made several telling statements that included: "Being alive with scleroderma is better than being dead"; "Being told you have a disability is like being told that you have 6 months to live"; "I'd rather be in a wheelchair than dead." Her choice to live regardless of her function demonstrated her recognition that on some level, somewhere, people question the existence of those who function differently. The value of life and the alternative of death were prominent in several narratives. Life was not always seen as having intrinsic value regardless of circumstance. For instance, a woman voiced a concern that she'd be "put on a ventilator and never get off" due to her disabling condition. There was no distinct line regarding what women would or would not value about life in any form, with any technology. The value placed on life differed; but no woman stated she did not value her life as currently experienced.

\section{A personal brush with death}

This category encompasses stories of participants' neardeath experiences. The impact of having closely faced death left many with varying perceptions of their ability to control death. A desire to prepare for something only a "higher power" could control was prominent. One participant described how gastric bypass surgery resulted in severe malnutrition that brought her very near to death.

"It was just my skin holding my body together, and I was in bed for more than 2 years, and all my muscles had atrophied. I had resigned that I was dying."

She later observed:

"I'm not going to let anything pull me down, and God has brought me this far. I've faced death so many times. It doesn't scare me."

Others described brushes with death as life-changing events that resulted in a variety of consequences. For example, one woman discussed two serious falls as brushes with death:

"I could have killed myself. I thought I was dead 'cause I hit so hard...I didn't know you could fall so hard and hit your head so hard that you couldn't breathe." 
Yet, she also observed that "God isn't finished with me." She subsequently decided to obtain long-term disability insurance because: "If I were to have an accident or anything...you just don't know what's gonna happen to me."

\section{Discussion}

Death emerged as a significant event within the participants' stories. References to another's death often served as a means for remembering the chronology of the participants' own life stories Yet, EOL issues also influenced participants' perspectives regarding their own and others' EOL trajectories. Participants expressed determination to remain as independent as possible within the context of declining functional ability and uncertainty regarding the future.

Many of the participants believed that a loved one's death triggered the onset or worsening of their disabling condition. This finding is consistent with studies that identify both caregiver burden and another's death as stressful events that can heighten risk for morbidity and mortality. ${ }^{19,20}$ In particular, studies reveal that psychological distress associated with bereavement can be associated with the onset or exacerbation of disabling diseases, including rheumatoid arthritis, fibromyalgia, and multiple sclerosis. ${ }^{21,22}$ Accordingly, clinicians should be cognizant of the physiologic impact of bereavement and implement interventions that mitigate risk for stress-related illness.

As the participants described EOL issues, some juxtaposed their struggles with daily life and with obtaining medical care against the alternative of dying. All stories revealed a sense of vulnerability about the future within the context of increasing disability. As such, "to feel vulnerable means to be, or to perceive oneself to be at risk of physical injury or of emotional or psychological wounding."23(p167) Many expressed such vulnerability as they feared the consequences of increasing dependence as disease progressed, and discussed the need for appropriate EOL care facilities. Further, spousal loss caused worries about living alone with a substantial disability, no care provider, and limited finances. This sense of vulnerability is a potential "spiral of cumulative disability"23(p168) that can result in inadequate EOL care. Lack of care options for PWDs is a problem in this context. Indeed, court cases granting requests to withhold or withdraw life-sustaining support from severely disabled persons have been framed as compassionate EOL care that supports patient autonomy and relieves suffering. These verdicts have been criticized as decisions to hasten death based on a very limited view of disability as suffering, or a fate worse than death. ${ }^{24-26}$ Nonetheless, little is known about the EOL experience for individuals with long-standing functional disabilities, and this warrants further investigation.

Participants' comments also revealed a sense of vulnerability regarding their use of life-sustaining technology and assistive devices. For example, a preference for renal dialysis and for wheelchair use over death was evident. Thus, what a nondisabled person might view as unwanted intrusive technology at the EOL may be embraced as an important part of daily living by a PWD. However, some authors view rejection of technological support in life-limiting illness as an important component of quality EOL care ${ }^{27}$ and advance care planning (ACP). ${ }^{28}$ Unfortunately, advance directives have been touted as a means to "escape from disability" at the EOL. ${ }^{29}$ Optimal approaches to ACP for PWDs have yet to be established. In the meantime, health care providers should carefully craft dialogues about ACP in which disability is not assumed to be associated with poor quality of life.

Although this study revealed a number of concerns pertinent to EOL care for PWDs, the nature of the study design precluded more in-depth understanding of the participants' issues. Hence, further studies using hermeneutic approaches are warranted. Because the participants were white, older women in Texas, the EOL experience in more diverse groups must be explored. Planning for quality EOL care that respects personal values and preferences requires attention to experiences and perspectives shared by persons with long-term functional disabilities. Although disparate health care and outcomes have been well documented in this population, EOL care issues for this group require further scrutiny.

\section{Acknowledgments}

This study was presented in part as a poster presentation at the 2011 American Academy of Hospice and Palliative Medicine Annual Assembly, February 16, 2011, Vancouver, British Columbia, Canada.

This study was funded by the National Institutes of Health/ National Institute of Nursing Research, R01 NR010360, T. Harrison (PI).

\section{Author Disclosure Statement}

No competing financial interests exist.

\section{References}

1. Braun UK, McCullough LB, Beyth RJ, Wray NP, Kunik ME, Morgan RO: Racial and ethnic differences in the treatment of seriously ill patients: A comparison of African American, Caucasian, and Hispanic veterans. J Natl Med Assoc 2008;100:1041-1051.

2. Bruera E, Sweeney C, Russell N, Willey JS, Palmer JL: Place of death of Houston area residents with cancer over a twoyear period. J Pain Symptom Manage 2003;26:637-643.

3. Cohen LL: Racial/ethnic disparities in hospice care: A systematic review. J Palliat Med 2008;11:763-768.

4. Barnato AE, Anthony DL, Skinner J, Gallagher PM, Fisher ES: Racial and ethnic differences in preferences for end-oflife treatment. J Gen Intern Med 2009;24:695-701.

5. Hanchate A, Kronman AC, Young-Xu Y, Ash A, Emanuel E: Racial and ethnic differences in end-of-life costs. Arch Intern Med 2009;169:493-501.

6. Mack JW, Paulk E, Viswanath K, Progerson HG: Racial disparities in the outcomes of communication on medical care received near death. Arch Intern Med 2010;170:1533-1540.

7. Muni S, Engelberg RA, Treece PD, Dotolo D, Curtis JR: The influence of race/ethnicity and socioeconomic status on endof-life care in the ICU. Chest 2011;139:1025-1033.

8. Stein GL, Kerwin J: Disability perspectives on health care planning and decision-making. J Palliat Med 2010;13:10591064.

9. American Community Survey. 2009. www.census.gov/acs/ www/[Last accessed June 3, 2011.]

10. Gill TM, Gahbauer EA, Han L, Allore, HG: Trajectories of disability in the last year of life. N Engl J Med 2010;362:11731180.

11. Healthy People 2020: Disability and health. http://healthy people.gov/2020/topicsobjectives2020/overview.aspx?topicid $=9$ [Last accessed June 3, 2011.] 
12. McCarthy EP, Ngo LH, Chirikos TN, Roetzheim RG, Li D, Drews RE, Iezzoni LI: Cancer stage at diagnosis and survival among persons with Social Security Disability Insurance on Medicare. Health Serv Res 2007;42:611-628.

13. Iezzoni L, Ngo LH, Li D, Roetzheim RG, Drews RE, McCarthy EP: Treatment disparities for disabled Medicare beneficiaries with Stage I non-small cell lung cancer. Arch Phys Med Rehabil 2008;89:595-601.

14. Byock I, Twohig JS, Merriman M, Collins K: Promoting excellence in end-of-life care: A report on innovative models of palliative care. J Palliat Med 2006;9:137-151.

15. Sandelowski M: What's in a name? Qualitative description revisited. Res Nurs Health 2010;23:334-340.

16. Warner DF, Brown TH: Understanding how race/ethnicity and gender define age-trajectories of disability: An intersectionality approach. Soc Sci Med 2011;72:1236-1248.

17. Harrison T: Burden of restraint, disablement, and ethnic identity: A case study of total joint replacement for osteoarthritis. Health Care Women Int 2011;32:669-685.

18. Patton MQ: Qualitative Research and Evaluation Methods, 3rd ed. Thousand Oaks, CA: Sage, 2002.

19. Christakis NA, Allison, PD: Mortality after the hospitalization of a spouse. N Engl J Med 2006;354:719-730.

20. Stroebe M, Schut H, Stroebe W: Health outcomes of bereavement. Lancet 2007;370:1960-1973.

21. Reser JE, Reser WW: Does rheumatoid arthritis represent an adaptive, thrifty condition? Med Hypoth 2010;74:189-194.

22. Grant I, Brown GW, Harris T, McDonald WI, Patterson T, Trimble MR: Severely threatening events and marked life difficulties preceding onset or exacerbation of multiple sclerosis. J Neurol Neurosurg Psychiatry 1989;52:8-13.
23. Stienstra D, Chochinov HM: Vulnerability, disability, and palliative end-of-life care. J Palliat Care 2006;22:166-174.

24. Gill CJ: No, we don't think our doctors are out to get us: Responding to the straw man distortions of disability rights arguments against assisted suicide. Disabil Health J 2010; 3:31-38.

25. Stienstra D, Ashcroft T: Voyaging on the seas of spirit: An ongoing journey towards understanding disability and humanity. Disabil Soc 2010;25:191-203.

26. Titchkosky T: Reading and Writing Disability Differently: The Textured Life of Embodiment. Toronto, ON: University of Toronto Press, 2007.

27. Heyland DK, Dodek P, Rocker G, Groll D, Gafni A, Pichora D, Shortt S, Tranmer J, Lazar N, Kutsogiannis J, Lam M; Canadian Researchers, End-of-Life Network (CARENET): What matters most in end-of-life care: Perceptions of seriously ill patients and their family members. CMAJ 2006; 174:627-633.

28. Levi BH, Dellasega C, Whitehead M, Green MJ: What influences individuals to engage in advance care planning? Am J Hosp Palliat Med 2010;27:306-312.

29. Holm RP: Escape from disability (on advanced directives and end-of-life care). S D Med 2008;61:142.

Address correspondence to: Deborah L. Volker, Ph.D., R.N. The University of Texas at Austin School of Nursing 1700 Red River Street Austin, TX 78701

E-mail: dvolker@mail.nur.utexas.edu 